\title{
On the Biology of Sagitta. The Breeding and Growth of Sagitta elegans Verrill in the Plymouth Area, $1930-31$.

\author{
By
}

F. S. Russell, D.S.C., B.A.,

Naturalist at the Plymouth Laboratory.

With 2 Figures in the Text and Plate I.

PlankTon animals are in intimate relation with the sea-water in which they live, and the physical conditions of this surrounding medium must have profound effects upon the general metabolism of such delicate organisms. One of the greatest problems in biology is an understanding of the differences that are shown in a single species according to its geographical distribution, probably caused, in marine animals, by differences in the conditions of the sea from place to place; in this respect variations in the sizes to which the animals grow are noticeable. Such differences also appear in a species in one locality when the successive broods are subject to varying conditions in the water brought about by seasonal changes. I have shown in my researches on the vertical distribution of plankton (11) that the copepod Calanus finmarchicus will behave differently at different seasons; and that this difference appears because we are dealing with separate broods which are probably physiologically distinct one from another. Similar differences are apparent also in the behaviour of other plankton animals. It has therefore proved necessary in a study of seasonal change in behaviour to know exactly how many distinct broods we are dealing with.

Since some confusion had existed concerning the species of Sagitta present in our Plymouth waters, it seemed that a close study of Sagitta broods would prove useful both in throwing light on the question of seasonal behaviour of different broods and also in clearing up the lifehistory of these animals, which are very common and characteristic in the plankton around our shores.

Evidence is also available that the seasonal change in size of different broods of marine animals bears some relation to the temperature of the sea-water in which they develop. If this be so it is necessary that the connexion should be more closely investigated. Research on populations of plankton animals is however much complicated by the possible introduction into the same area of animals from different water masses 
which differ in physical and chemical conditions. A study of the effects of seasonal change in temperature would be very difficult in such areas because one would never be certain that the population under examination was always the indigenous one. The waters of the English Channel near Plymouth are however perhaps rather suitable for this research; continuous hydrographical observations have shown that there seem to be years in which there is little interchange of waters of widely differing characteristics, such as is found for instance in regions where waters of Polar and of Gulf Stream origin intermingle.

A careful examination of the Chætognath population at Plymouth has proved that there are two species which predominate in the plankton, Sagitta elegans Verrill* and Sagitta setosa J. Müller. In addition, during a year's collections three specimens of adult Sagitta serratodentata Krohn have been found, but this species can probably only be regarded as an occasional invader of the region under survey. $\dagger$

In these pages I shall deal only with Sagitta elegans, describing its growth and breeding throughout a year. A similar study has been made of $S$. setosa and it is hoped to publish this in a later paper, when the two species will be compared.

\section{Methods of Study.}

Since one of the objects of this research was to gain a knowledge of the size to which Sagitta grows at various seasons of the year it was necessary that the collections should provide as many of the adult individuals as possible. For this purpose the 2-metre stramin ring-trawl is the most suitable net, and as weekly collections are made with this net to study the seasonal abundance of young fishes it was decided to make the collection serve both ends. Ideally it would have been necessary to take also concurrent hauls with a silk net to sample efficiently the young Sagitta population, but an examination of two sets of collections would have been too lengthy when it was probable that the use of the stramin net alone would produce the desired data.

Collections were made once a week in daylight at a position 2 miles east of the Eddystone lighthouse in water about 54 metres in depth; on every occasion oblique hauls $(12$, p. 640$)$ were taken in order to sample all water layers, and each haul was half an hour in duration. My thanks are due to Captain V. Lord and the crew of s.s. Salpa for their continuous care in making these weekly collections.

In each catch the total number of Sagitta (preserved in $5 \%$ formalin) was found, either by complete count, or by sample method $(10$, p. 776$)$ if

* I am greatly indebted to Dr. H. B. Bigelow, Miss Beale, Dr. A. G. Huntsman, and Professor A. Meek for confirmation in the identification of this species.

$\dagger$ Two of these were taken on May $7 \mathrm{th}, 1930,16 \frac{1}{2}$ and $15 \mathrm{~mm}$. in length; one on September 3rd, 1930, $12 \mathrm{~mm}$, in length. All three were fully mature. 
the catches were large. An adequate sample was then measured in length to the nearest half millimetre below. Great care was taken that those measured were secured by fair sampling means in order that a true picture of the size distribution should be obtained on each occasion. In measuring, the tail fin was excluded, the length being that from the tip of the snout to the base of the tail. Measurements have usually been give by other workers (e.g. 2 and 4 ) including the tail fin, but as this membrane is so liable to damage it was thought advisable where such
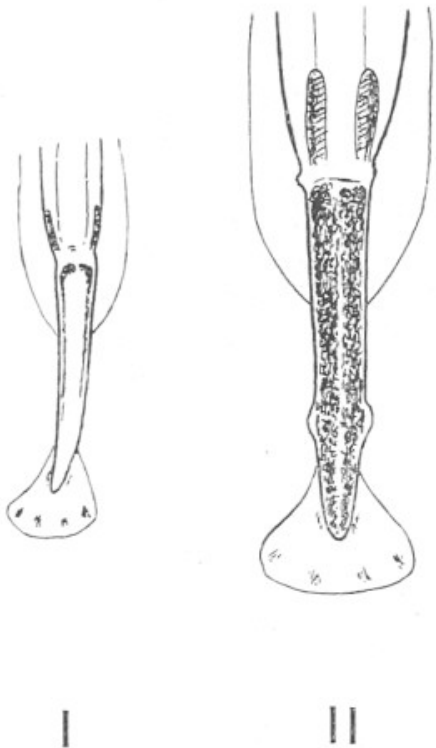
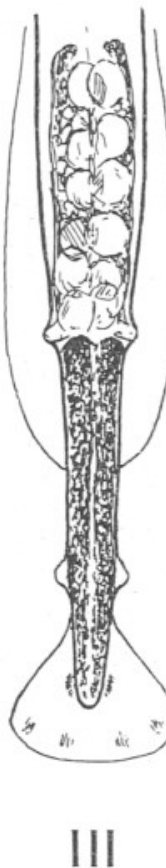

Text-Fig. 1.-The three stages of maturity used as criteria of development in Plate I. I, upper limit of Stage I; II, upper limit of Stage II ; III, ripe adult in Stage III. Stained in alum carmine; the proportions appear narrower than natural owing to shrinkage.

large numbers were being dealt with that the more defined end of the body should be regarded as the posterior limit. Actually in the larger specimens the tail fin is just over half a millimetre in length beyond the end of the body, being proportionately slightly smaller in the younger stages. The addition of half a millimetre to my measurements will therefore give a sufficiently approximate idea of the total length of the animal.

After measuring, 30 to 60 individuals were selected to supply a good sample covering the complete range of lengths obtained. These were stained in alum carmine to emphasize the gonads and mounted in Canada 
balsam. The stained specimens were examined under the microscope to find the state of maturity or otherwise of the gonads in relation to the body length.

Sagitta is a hermaphrodite animal in which the male organs mature first. The testes are situated in the posterior section of the body, or tail, and this portion becomes filled with spermatozoa and maturing spermatocytes. It is only after this stage is reached that the ovaries begin to ripen fully. The state of maturity of the animal could thus be very conveniently divided into three easily separated stages (Text-Fig. 1). Stage I included all the youngest Sagitta in which not a single sperm mother cell was visible lying loose in the tail cavity. Stage II ranged between those individuals with the first appearing spermatocytes and those in which the tail segment was packed with spermatocytes and spermatozoa, but in which the ovaries, while appearing evident, showed little sign of swelling eggs (Text-Fig. 1). Stage III contained those individuals in which the ovaries were fully ripe or ripening. The measurements obtained were the upper limit in length of those in Stage I, the upper and lower limits of those in Stage II, and the lower limit in length of Stage III. Thus often an overlapping occurred between Stages I and II and Stages II and III as was to be expected. During the process of staining and mounting some shrinkage of the animals takes place, which may amount in the longer individuals to as much as half a millimetre; no correction has been made for this shrinkäge as it it so small as not materially to affect the general picture.

In Tables I to III on pages 143 to 145 are given the full number of Sagitta occurring in each collection, the results of the measurements of total length, and the data obtained from the examination of the stained specimens.

\section{General Results.}

The results of the research have been reproduced in a complete form in Plate I, in which the length distribution on each day has been reduced to a percentage basis and the data regarding state of maturity have been incorporated. This diagram, which covers the period May, 1930, to May, 1931, appears to show clearly that a brood of large individuals spawning

\section{EXPLANATION OF PLATE I.}

Plate I.-The percentage size distribution of Sagitta elegans caught in the ring-trawl on the days given. The black, eross-hatched and shaded areas represent the various stages of development (see top of diagram for key). In this diagram the lines of demarcation between different stages must not be taken as being exact, as possible shrinkage has not been taken into account. It must also be realised that the Stage III includes both ripening and mature females, and they must not be regarded as all fully mature, though usually probably the majority are so. 
Journ. Mar. Biol. Assoc. XVIIIL-1.

$$
\square \text { STAGE I ST. II }
$$

- ST. III

[IT] ST I+ II

ST. II+ III

口 ST. I+ III

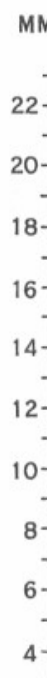

MM

$22-$
20
18
16
14
12
10
8
6
4

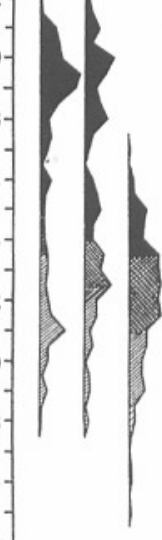

1930

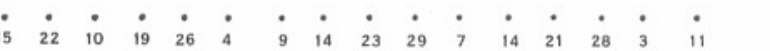

SAGITTA ELEGANS.

$0102030 \%$
(2T. I+II+II

PLATE L

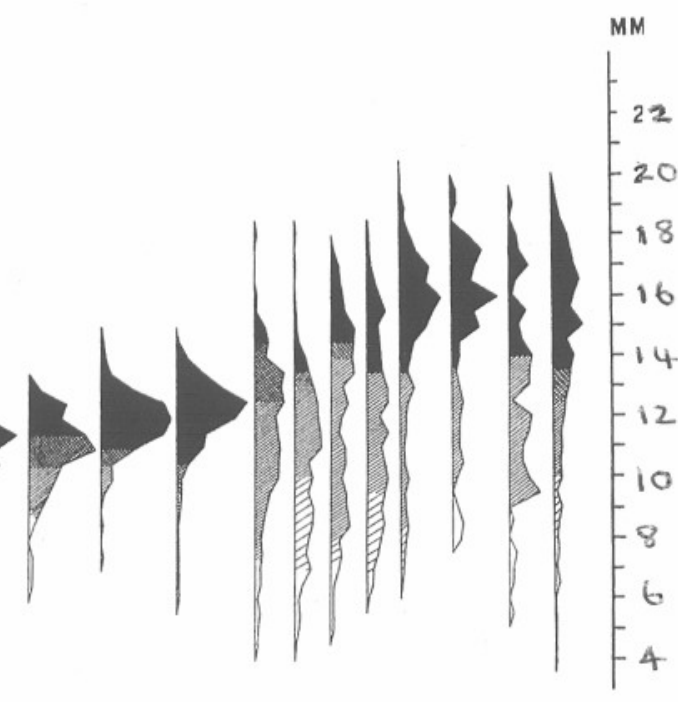

FEBRUARY IMARCH' APRIL I MAY 
in May gave rise to a brood spawning in June and July, the latest individuals of which may themselves have arisen from the early June spawners. The July spawners produced a brood which did not fully mature until September. The offspring of the September spawners developed no gonads during October and November; in December the male organs were ripening, and in January the ovaries started to mature. A complete spawning population was thus formed in February. These adults again gave rise to a large brood spawning in April and May.

During the twelve months beginning June, 1930, and ending May, 1931, there were apparently therefore four different broods of Sagitta elegans, and possibly five if two broods can be accounted for in June and July during which time spawning is probably intermittent.

The diagram shows very clearly the ripening of the male products preparatory to the full maturity of the individual, and indicates also the overlapping that occurs between the different stages of development. In October there is an overlapping of the remaining adults of the September breeding population and their offspring in which no gonads are developed until the male organs start to ripen in December.

A pronounced feature is the absence of the younger stages, which is probably entirely due to the coarseness of the mesh of the stramin net used for collecting. On each occasion, however, there is an indication of the arrival of the young of new broods in the catches at the periods when probably in fact they are far more numerous than the adults. The closing up of the length-distribution curves to form compact breeding populations is also especially noticeable in September.and February.

Inspection of Plate I also shows"that there was a definite difference in the length attained by the adults in each successive brood. The approximate average lengths of the adults of the different broods as determined by inspection of the graphs in Plate I, without calculation, were as follows :-

\begin{tabular}{|c|c|c|c|}
\hline May, 1930 & & & $19 \frac{1}{2}-20 \mathrm{~mm}$. \\
\hline June, 1930 & & & $13 \frac{1}{2}-14 \frac{1}{2} \mathrm{~mm}$. \\
\hline July, 1930 & & & ca. $13 \mathrm{~mm}$ \\
\hline September, 1930 & & & $10-10 \frac{1}{2} \mathrm{~mm}$. \\
\hline February, 1931 & & & $12-12 \frac{1}{2} \mathrm{~mm}$. \\
\hline April-May, 1931 & & & ca. $16 \mathrm{~mm}$ \\
\hline
\end{tabular}

Coincident with this was a difference in the size at which the different broods matured, the broods with smallest adults maturing at a smaller size than those with the largest (See Plate I).

In Text-Figure $2 \mathrm{I}$ have summarised the above results and included the curve for the seasonal change in the temperature of the water. In this figure the temperatures are given for the surface at the International 
Station L5 near the Eddystone and for 25 metres at the station E1 ten miles beyond the Eddystone.* It is probable that for the months October to May this represents fairly accurately the temperature conditions at all depths in the locality where the collections of Sagitta were made; from June to September the temperature of the deeper layers was probably somewhere between that of the surface at L5 and that at $25 \mathrm{~m}$. at E1, but nearer to those at E1. The black areas in TextFigure 2 indicate the chief times of spawning as apparently shown by Plate I, and these are plotted against the average length of the spawning adults. The decrease in the length to which the Sagitta grew as the temperature rose is very evident, the smallest size occurring in September. Although the Sagitta spawning in February were born under higher temperature conditions than were those spawning in September they attained a slightly greater size; but during the period of their growth the temperature was falling and also they lived for a very much longer time than those of any other brood. It is probable that the size reached is conditioned amongst other things by the amount and type of food eaten, the temperature conditions, and the length of life, and that the latter depends on the time of the onset of maturity. At the top of TextFigure 2 are given the periods of days elapsing between the last dates on which the different spawning populations were abundant, and this possibly gives some idea of the length of life of the Sagitta at different times of the year on the assumption that they die after spawning as seems to be indicated by Plate I. $\dagger$ As one would expect, the time taken to reach maturity is longer in the colder months than in the warmer; those born in February taking 94 days to full maturity in May, as against 43 days for those born at the end of July which matured inSeptember. The length of life for the June and July brood is given as covering the whole of this period but it is probable that it should be split. The longest-lived Sagitta were undoubtedly those born in September. These did not mature until February, a period of 165 days ; it must be realised, however, that for two months at any rate of this period there was no gonad development. The stimulus for gonad development was possibly removed by the high temperature in October when the water at all depths reached a temperature of over $14^{\circ} \mathrm{C}$., and it is possible that somewhere in the neighbourhood of this temperature lies the limit at which successful reproduction is no longer possible. It was noticeable also that the ovaries of the September breeding population showed rather an unhealthy appearance and contained few ripe eggs,

* I am indebted to Mr. H. W. Harvey and Dr. L. H. N. Cooper for the temperature records at these stations. The salinity range was of the order of $35.00 \% \pm \cdot 20$; the full data will be obtainable from the Rapport Altantique of the International Council for the Exploration of the Sea for 1930 and 1931.

$\dagger$ Kramp ( $\%$, p. 36) says: "Undoubtedly the animal dies when the eggs have been spawned." 
and there was evidence that gonad development was somewhat retarded during August. During June the majority of the Sagitta would experience the temperature of the lower water layers, but as the warming of the surface waters extends to greater and greater depths during July and August many individuals must experience high temperature conditions.

After the temperature of $14^{\circ} \mathrm{C}$. had been passed there was no further

DAYS.
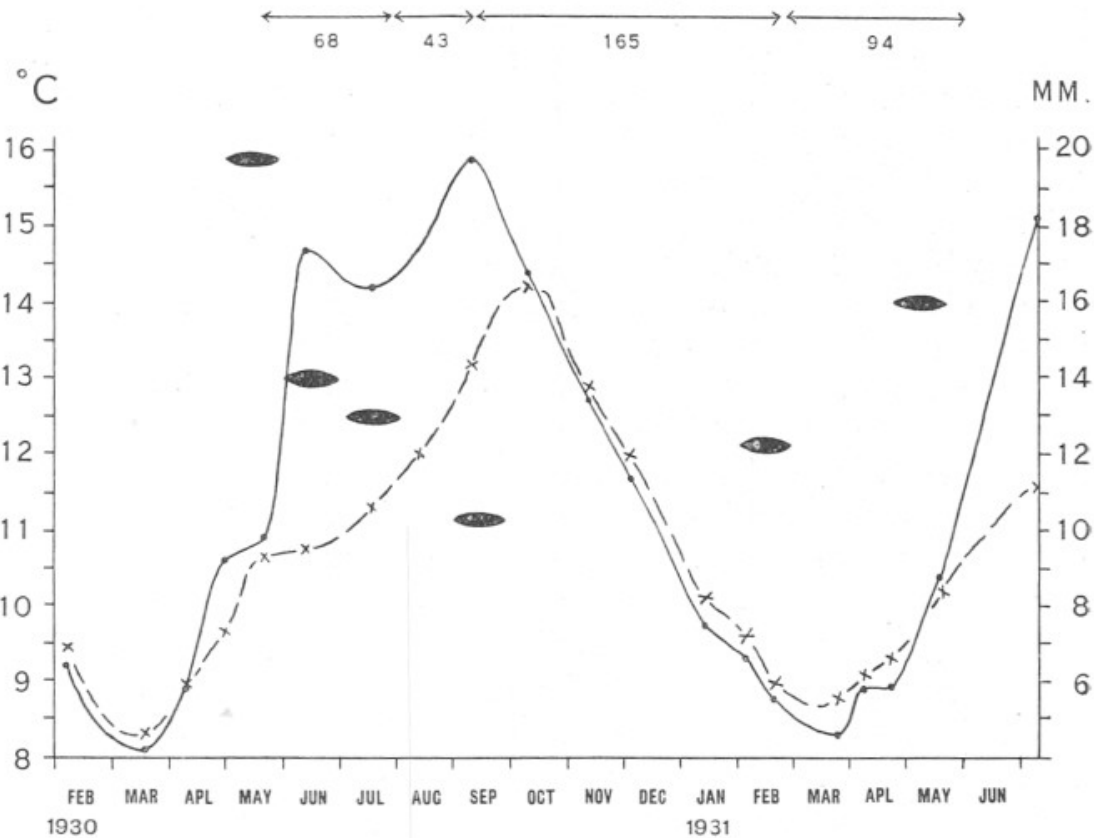

Text-Fig. 2.-Curves of Temperature at surface at international station L5 (- - ) and at 25 metres at E1 ( - - ), February, 1930, to June, 1931. Superimposed on these are the periods of spawning of the different broods of S. elegans (black areas) plotted against the approximate average length of the adults of each brood. (Left coordinate, temperature in ${ }^{\circ} \mathrm{C}$.; right coordinate, length in millimetres.) Above are given the approximate periods between the times of spawning.

sign of developing gonads until the water had cooled to nearly $11^{\circ} \mathrm{C}$. in December when the male organs started to develop; following on the development of the male organs the ovaries did not ripen until a temperature of about $10^{\circ} \mathrm{C}$. was reached in January.

A further point of interest is that the large adults of the spring of 1931 did not grow to so great a length as did those of the spring of 1930, the average and maximum lengths being for each year 16 and $20 \frac{1}{2} \mathrm{~mm}$. and $19 \frac{1}{2}-20$ and $22 \mathrm{~mm}$. respectively. It is to be noticed that the temperature in 1930 was about half a degree lower than that in 1931 ; there is some evidence also that the 1930 brood was born earlier than that of 
1931 and would therefore have had a longer period in which to grow. This difference in size attained in different years is a phenomenon that may throw light on the effects of temperature on growth, but it is not proposed to discuss it further until more data are available for different years.

\section{On the Length of Mature Ovaries.}

During the examination of the mounted specimens some measurements were made of the length of the mature ovaries. The ovaries were regarded as mature when they contained one or more fully distended eggs. By a number of measurements of the eggs in situ in the mounted material it was found that the average diameter of the largest eggs lay between $\cdot 334$ and $.394 \mathrm{~mm}$. This agrees fairly with figures given by Huntsman and Reid (6, p. 103) in which the diameters for the largest eggs lay between $\cdot 310$ and $\cdot 446 \mathrm{~mm}$.

There is naturally a decrease in the length of the ovaries throughout the season as the successive adults are smaller, but this decrease is not in direct proportion to that of the length. I give below figures showing the average length of ripe ovaries for adults of different sizes, and also the ratio ovary-length/body-length. These show clearly that in the smaller adults the length of the ovary is less in proportion to the total length of the body than it is in the larger adults, being about constant from 10 to $14 \mathrm{~mm}$. and then increasing gradually.

$\begin{array}{ccccc}\begin{array}{c}\text { Length } \\ \text { of adults in mm. }\end{array} & & \begin{array}{c}\text { Average length } \\ \text { of ovary in mm. }\end{array} & & \begin{array}{c}\text { Ovary-length } \\ \text { Body-length. }\end{array} \\ 9.5 & \ldots & 0 \cdot 55 & \ldots & 0 \cdot 061 \\ 10 & \ldots & 0 \cdot 71 & \ldots & 0 \cdot 075 \\ 10 \cdot 5 & \ldots & 1 \cdot 01 & \ldots & 0 \cdot 101 \\ 11 & \ldots & 1 \cdot 19 & \ldots & 0 \cdot 113 \\ 11 \cdot 5 & \ldots & 1 \cdot 14 & \ldots & 0 \cdot 104 \\ 12 & \ldots & 1 \cdot 10 & \ldots & 0 \cdot 096 \\ 12.5 & \ldots & 1 \cdot 36 & \ldots & 0 \cdot 113 \\ 13 & \ldots & 1 \cdot 21 & \ldots & 0 \cdot 097 \\ 13 \cdot 5 & \ldots & 1 \cdot 30 & \ldots & 0 \cdot 100 \\ 14 & \ldots & 1 \cdot 49 & \ldots & 0 \cdot 110 \\ 14.5 & \ldots & 1 \cdot 65 & \ldots & 0 \cdot 111 \\ 15 & \ldots & 1.95 & \ldots & 0 \cdot 112 \\ 15.5 & \ldots & 2 \cdot 22 & \ldots & 0 \cdot 130 \\ 16 & \ldots & 2 \cdot 22 & \ldots & 0 \cdot 143 \\ 16.5 & \ldots & 2 \cdot 76 & \ldots & 0 \cdot 139 \\ 17 & \ldots & 3 \cdot 20 & \ldots & 0 \cdot 167 \\ 17.5 & \ldots & 2 \cdot 94 & \ldots & 0 \cdot 188 \\ 19 & \ldots & 3 \cdot 69 & \ldots & 0 \cdot 194 \\ 20 & \ldots & 3.86 & \ldots & 0 \cdot 193\end{array}$


Seeing that there is no evidence of any very marked decrease in the diameter of the ripe eggs at the different times of the year it follows from the above figures that the number of offspring produced per parent must be very much greater in the early months of the year when the adults grow to a large size. In fact, in the late summer adults one rarely sees more than one or two ripe eggs present at a time.

Fully spent adults were rarely seen, which agrees with Kramp's observations ( $\%$, p. 36) ; they were most noticeable however among the remnants of the large May brood that lived over into June. It was also noticed that in many of those individuals which contained a nematode or trematode parasite the ovaries failed to develop; in obtaining the data on state of maturity for Plate I these were ignored.

As regards the actual number of Sagitta occurring in the catches it is unwise to draw conclusions from one year's results only, on account of errors due to swarming. The full data are given in Table I, page 143, and except for one catch of 7502 individuals on March 17th, 1931, there seems to be some indication that in the year under review the Sagitta were definitely most abundant during the months July and August, and the beginning of September. These would be the offspring of the June and July spawners. It has already been remarked above that the ovaries of the September breeding population appeared unhealthy, perhaps on account of the high temperature, and the figures appear to bear out this as they indicate that the brood arising from the September spawning was only a small one. There is also a tendency shown for each successive brood to decrease in numbers from their first appearance in the catches to the appearance of the succeeding brood.

\section{OBSERVATIONS FROM OTHER LOCALITIES.}

It is hard to compare my data with those from elsewhere as there has been little work done that covers the period of a whole year. In general the change in size of adults at different times of the year has been realised, but no very definite data have been obtained. Bigelow (1, p. 320), for instance, says for the Gulf of Maine that "the adults average decidedly larger (up to 35 millimetres long) in March and April, when the temperature is near its lowest for the year, than in summer." The difference in the size at maturity of Sagitta from place to place has been well shown by Huntsman (5, p. 446), but owing to the difference in the temperatures at different depths and the intermingling of water masses in the region in which he worked it is impossible to find the exact relationship between temperature and size attained. As regards the breeding periods, Huntsman and Reid (6) by examination of ovaries concluded that in the Bay of Fundy, " the spawning season is a long one, extending from the end of 
March or the beginning of April to September at least. September 4th would seem to be near the end of the season, as at that time a smaller proportion of individuals contained large eggs than previously." From their figures (6, p. 103) there was evidently no such period of the year when the nearly full-grown Sagitta were entirely without gonads as occurred off Plymouth during October and November. Bigelow (1, p. 315), for the Gulf of Maine, says, "On the whole, then, it is safe to say that S. elegans is a late spring and summer breeder in the Gulf of Maine, in so far as any considerable production is concerned, but probably it reproduces more or less throughout the entire year." Fish, for the Woods Hole region, says. that in March and April, 1923, the S. elegans were ripe, and that the eggs. were common in the plankton in April. He also says (3, p. 134) that " in the 16 years that $S$. elegans has been recorded, with one or possibly two exceptions, none appeared before November or remained after July." From a temperature curve given by Fish it would appear that the temperatures between July and November were falling from about $20^{\circ}$ C. to $10^{\circ}$ C. $\operatorname{Kramp}(\boldsymbol{\%}$, p. 38), after examination of specimens taken in July and August, says, "At most stations small and full-grown specimens were found together, which indicate that the breeding period in the Greenland waters extends over a considerable space of time, though the relative numbers of individuals of the different groups at different times seem to indicate that the bulk of the specimens breed in the autumn."

From data given by Meek (8) for the North Sea ther is evidently a change in size, during the year, but stages of maturity are not given. From his text-figures on pages 750 and 751 the largest Sagitta would appear to be as follows:-

\begin{tabular}{|c|c|c|c|}
\hline April, 1924 & . $20 \mathrm{~mm}$. & April, 1925 & $16 \mathrm{~mm}$. \\
\hline July, 1924 & $14 \mathrm{~mm}$. & June, 1925 & $21 \mathrm{~mm}$. \\
\hline August, 1924 . & $12 \mathrm{~mm}$. & July, 1925 & $17 \mathrm{~mm}$. \\
\hline September, 1924 & $13 \mathrm{~mm}$. & September, 1925 & $10 \mathrm{~mm}$. \\
\hline October, 1924 . & . $18 \mathrm{~mm}$. & & \\
\hline
\end{tabular}

According to Ritter-Záhony the distribution of S. elegans is (9, p. 17) $S$. elegans elegans, in Atlantic and apparently Pacific Ocean from $45^{\circ} \mathrm{N}$. to the ice sea on the surface.* S. elegans arctica, Northern ice seas, circumpolar on the surface; S. elegans baltica, Baltic.

The largest size given is $52 \mathrm{~mm}$. by Huntsman (5, p. 446) for the waters. of the Eastern Atlantic.

\footnotetext{
* Has been recorded as far south as the Canary Isles by L. Germain and L. Joubin (Res. Camp. Sei. Albert I, Monaco, Fasc. XLIX, 1916, p. 6).
} 


\section{SUMMARY.}

1. A study of the adult population of Sagitta elegans Verrill has been made in the waters off Plymouth by weekly collections with the 2-metre stramin ring-trawl hauled obliquely in the daylight.

2. Measurements of large samples and a study of the state of development of the gonads has shown that there were apparently four, if not five, broods of S. elegcns produced in the year.

3. These successive broods were apparently spawning in April-May, June-July, and September, 1930, and February, 1931.

4. In the offspring of the September spawning population no gonads were developed during October and November. The male organs started to ripen in December, and the ovaries in January, but the brood did not appear to be fully mature until February.

5. There was a difference in the size to which the adults of the different broods grew and at which they matured. The approximate average lengths of the adults of the spawning populations were in 1930 for May, $19 \frac{1}{2}-20 \mathrm{~mm}$. ; June, $13 \frac{1}{2}-14 \frac{1}{2} \mathrm{~mm}$. ; July, ca. $13 \mathrm{~mm}$. ; September,

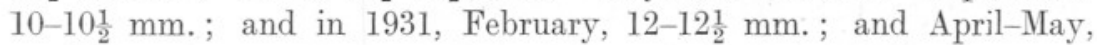
ca. $16 \mathrm{~mm}$.

6. Measurements of the ovaries of mature animals showed that in the smaller individuals the length of the ovary is less in proportion to the total length of the body than it is in the adults.

7. Very few fully spent individuals were to be seen; the ovaries failed to develop in many of those Sagitta which were parasitised by nematodes.

8. In the total catches the Sagitta were most abundant during July, August and the beginning of September.

\section{LITERATURE.}

1. Bigelow, Henry B. Plankton of the Offshore Waters of the Gulf of Maine. Bull, Bur. Fish., Washington, Doc. No. 968, Vol. XL, 1924, Part II, pp. 1-509, 1926.

2. Burfield, S. T., and Harvey, E. J. W. The Chætognatha of the Sealcrk Expedition. Trans, Linn. Soc. 2nd Ser., Zoology, Vol. XIX, Part I, 1926.

3. Fish, Charles J. Seasonal Distribution of the Plankton of the Woods Hole Region. Bull. Bur. Fish., Washington, Doc. No. 975, Vol. XLI, 1925, pp. 91-179, 1925. 
4. Fowler, G. H. The Chætognatha of the Siboga expedition. Siboga. Exped. Monogr., XXI, Leiden, 1906.

5. Huntsman, A. G. Some Quantitative and Qualitative Plankton Studies of the Eastern Canadian Plankton. Canadian Fisheries Expedition, 1914-1915, pp. 405-485, 1919, Ottawa.

6. Huntsman, A. G., and Reid, Margaret E. The Success of Reproduction in Sagitta elegans in the Bay of Fundy and the Gulf of St. Lawrence. Trans. Roy. Canadian Inst., Toronto, Vol. XIII, Part 2, pp. 99-112, 1912.

7. Kramp, Paul L. Chætognatha collected by the Tjalfe Expedition to the west coast of Greenland in 1908 and 1909 . Vidensk. Medd. fra Dansk. naturhist. Foren., Bd. 69, pp. 17-55, 1917.

8. Meek, Alexander. On Sagitta elegans and Sagitta setosa from the Northumbrian Plankton, with a Note on a Trematode Parasite. Proc. Zool. Soc. London, 1928, No. 29, pp. 743-776.

9. Ritter-ZÁhony, Rudolf von. Vermes. Chætognathi. Das. Tierreich. Leif. 29, pp. 1-34, Berlin, 1911.

10. Russeld, F. S. The Vertical Distribution of Marine Macroplankton. An Observation on Diurnal Changes. Journ. Mar. Biol. Assoc., N.S., Vol. XIII, No. 4, pp. 769-809, 1925.

11. _ The Vertical Distribution of Marine Macroplankton. VII. Observations on the Behaviour of Calanus finmarchicus. Ibid. Vol. XV, No. 2, pp. 429-454, 1928.

12. — The Vertical Distribution of Marine Macroplankton. IX. The Distribution of the Pelagic Young of Teleostean Fishes in the Daytime in the Plymouth Area. Ibid. Vol. XVI, No. 2, pp. $639-676,1930$. 


\section{TABLE I.}

\section{Total Numbers of Sagitta elegans in Ring Trawl Collections.}

\begin{tabular}{|c|c|c|c|c|c|c|c|c|c|c|c|}
\hline May & 15 th, & 930 & 243 & Sept. & 24 th, & 1930 & 270 & Jan. & 26th, & 1931 & 117 \\
\hline & $22 \mathrm{nd}$ &, & 101 & Oct. & lst & ,, & 102 & Feb. & 6 th & , & 51 \\
\hline June & 10th & , & 1324 & , & 7 th & , & 74 & , & 12th & , & 83 \\
\hline , & 19th & , & 637 & ," & 14th & ," & 303 & , & 20th & , & 816 \\
\hline & 26th & , & 760 & $"$ & 16th & , & 229 & & 23rd & , & 474 \\
\hline July & 4th & , & 2218 & Nov. & 6 th & , & 441 & March & $17^{\text {th }}$ & , & 7502 \\
\hline ", & 9 th & , & 4377 & , & 13th & ,, & 159 & & 26th & , & 491 \\
\hline , & 14th & , & 3942 & , & 20 th & , & 32 & April & lst & , & 935 \\
\hline ,, & $23 \mathrm{rd}$ & , & 2142 & ", & 26th & , & 61 & ," & 9 th & , & 638 \\
\hline & 29 th & , & 1423 & Dec. & 3rd & , & 730 & , & 16th & , & 764 \\
\hline Aug. & 7 th & , & 7800 & $"$ & loth & , & 360 & , & $22 \mathrm{nd}$ & ,, & 76 \\
\hline , & 14th & , & 5210 & ," & 17th & , & 262 & & 30 th & , & 18 \\
\hline ," & 2lst & , & 2038 & ," & $22 \mathrm{nd}$ & ,', & 72 & May & 6 th & ," & 91 \\
\hline & 28 th & , & 1018 & Jan. & 1st, & 1931 & 210 & , & 13th & , , & 7 \\
\hline pt. & 3rd & ," & 1222 & , & 5 th & , & 109 & , & 28 th & , & 786 \\
\hline , & 11th & ", & 4398 & ," & 15th & , & 1765 & & & & \\
\hline & 16 th & ,, & 558 & ,, & 22nd &, & 172 & & & & \\
\hline
\end{tabular}

\section{TABLE II.}

\section{Results of Examination of Stained Specimens of S. elegans} for State of Maturity: Lengths in Millimetres.

St. I. St. II. St. III.

Upper Lower Upper Lower

Date. limit. limit. limit. limit. 1930

$\begin{array}{cr}\text { May } & 15 \text { th } \\ \text { June } & 22 \text { nd } \\ \text { 10th } \\ ,, & 19 \text { th } \\ \text { July } & 26 \text { th } \\ 4 \text { th } \\ ,, & 9 \text { th } \\ , & 14 \text { th } \\ ,, & 23 \text { rd } \\ , & 29 \text { th }\end{array}$

Aug. 7 th

, 14 th

, 21 st

, 28th

Sept. 3rd

, 11th

,16th

, 24th

Oct. lst

, 7 th

14 th

, 16th

Nov. 6th

$\begin{array}{cccc}- & 8 \frac{1}{2} & 15 & 13 \frac{1}{2} \\ - & 8 & 14 & 12 \frac{1}{2} \\ 8 \frac{1}{2} & 7 \frac{1}{2} & 13 \frac{1}{2} & 11 \\ 8 \frac{1}{2} & 7 \frac{1}{2} & 12 \frac{1}{2} & 12 \frac{1}{2} \\ 8 & 7 \frac{1}{2} & 12 & 11 \\ 7 \frac{1}{2} & 8 \frac{1}{2} & 13 \frac{1}{2} & 13 \\ 9 & 7 & 12 & 12 \\ 10 & 7 & 12 \frac{1}{2} & 12 \\ 10 \frac{1}{2} & 7 \frac{1}{2} & 12 \frac{1}{2} & 12 \\ 8 \frac{1}{2} & 8 & 12 \frac{1}{2} & 12 \\ 9 & 8 & 13 \frac{1}{2} & 12 \frac{1}{2} \\ 9 & 7 \frac{1}{2} & 12 \frac{1}{2} & 12 \\ 7 \frac{1}{2} & 8 \frac{1}{2} & 12 & 10 \\ 8 & 7 \frac{1}{2} & 11 & 10 \frac{1}{2} \\ 7 & 7 & 10 \frac{1}{2} & 10 \\ - & 7 \frac{1}{2} & 9 & 9 \\ 9 & 5 \frac{1}{2} & 9 \frac{1}{2} & 9 \frac{1}{2} \\ 10 & 8 \frac{1}{2} & 10 & 10 \\ 11 & - & 9 \frac{1}{2} & 8 \frac{1}{2} \\ 12 & - & 11 & 10 \\ 12 \frac{1}{2} & 9 \frac{1}{2} & 11 \frac{1}{2} & 10 \\ 12 & - & 11 \frac{1}{2} & -* \\ 12 & - & - & - \\ 13 & -\dagger & - & - \\ & & & \end{array}$

St. I. St. II. St. III.

Upper Lower Upper Lower

Date. limit. limit. limit. limit. 1930

Nov. 20th

, 26th 11 —*⿻一𠃋火

Dec. 3rd $12 \frac{1}{2} \quad 9 \frac{1}{2} \quad 13 \frac{1}{2} \quad-$

, 10 th

, 17 th

22 nd 1931

$\begin{array}{llll}13 & 10 \frac{1}{2} & 13 & -\end{array}$

Jan. lst

$11 \frac{1}{2} \quad 10 \quad 13 \frac{1}{2} \quad$ -

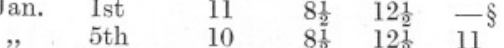

$\begin{array}{llllll}, & 15 \text { th } & 10 & 10 & 12 \frac{1}{2} & 10\end{array}$

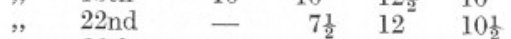

$\begin{array}{lllll}\text {, 26th } \quad-\quad 7 \frac{1}{2} & 11 \frac{1}{2} & 10\end{array}$

$\begin{array}{rrrrr}6 \text { th } & - & - & 10 \frac{1}{2} & 10\end{array}$

$\begin{array}{lllll}12 \text { th } & 7 & 9 & 11 \frac{1}{2} & 10 \frac{1}{2}\end{array}$

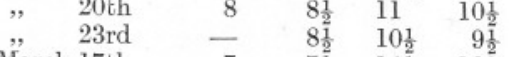

$\begin{array}{lllll}\text { March 17th } & 7 & 7 \frac{1}{2} & 14 \frac{1}{2} & 12 \frac{1}{2}\end{array}$

$\begin{array}{lrrrrr}\text { " } & 26 \text { th } & 10 & 7 & 13 \frac{1}{2} & 13\end{array}$

$\begin{array}{llll}8 & 7 \frac{1}{2} & 14 \frac{1}{3} \| & 14\end{array}$

$\begin{array}{llll}9 \frac{1}{2} & 7 & 13 \frac{1}{2} & 13 \frac{1}{2}\end{array}$

$\begin{array}{llll}8 \frac{1}{2} & 7 & 13 \frac{1}{2} & 13 \frac{1}{2}\end{array}$

$\begin{array}{llll}8 \frac{1}{2} & 10 & 12 \frac{1}{2} & 14\end{array}$

$\begin{array}{llll}10 & 8 & 13 \frac{1}{2} & 15\end{array}$

$\begin{array}{llll}6 \frac{1}{2} & 9 & 14 \frac{1}{2} & 13 \frac{1}{2}\end{array}$

$\begin{array}{llll}10 & 8 & 13 \frac{1}{2} & 12 \frac{1}{2}\end{array}$

* 1 only at $9 \frac{1}{2}$.

+1 at $12 \mathrm{~mm}$. with a few sperm morulæ.

$\ddagger$ One with ovary nearly ripe.

$\dagger+2$ at $11 \mathrm{~mm}$.

$\S 1$ at $13 \frac{1}{2} \mathrm{~mm}$.

** 1 at $11 \mathrm{~mm}$.

II 1 at $15 \frac{1}{2}$. 


\section{TABLE III.}

Measurements of Body Length of Sagitta elegans in Millimetres.

Length in $\mathrm{mm}$.

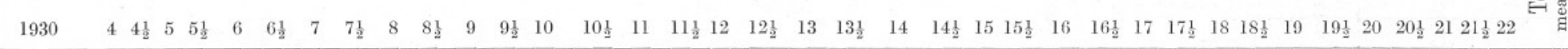

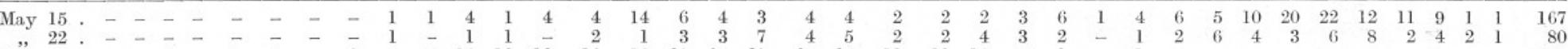

June 10:

, $19 .-\ldots$

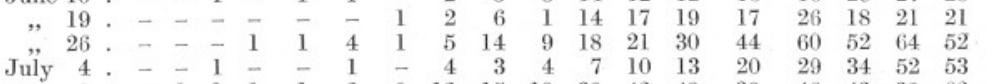

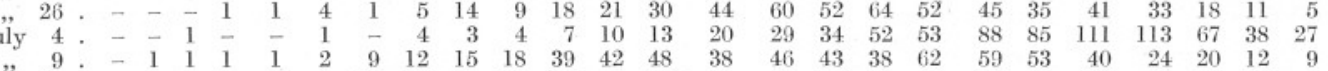

,, 14 . - -

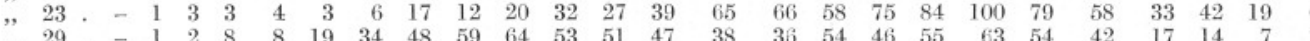

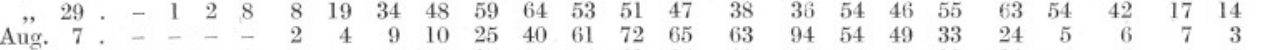

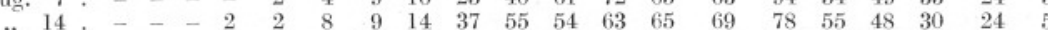

$\begin{array}{llllllllllllllllllllll}21 & - & - & 1 & 5 & 4 & 14 & 17 & 33 & 48 & 64 & 70 & 78 & 91 & 86 & 64 & 43 & 10 & 8 & 3\end{array}$

$\begin{array}{llllllllllllllllll}., & 28 & 1 & 9 & 5 & 27 & 29 & 45 & 48 & 47 & 58 & 62 & 65 & 70 & 54 & 49 & 13 & 7\end{array}$

sept. 3. - $\begin{array}{rrrrrrrrrrrrrrrrr}- & 1 & 2 & 7 & 21 & 22 & 42 & 41 & 46 & 60 & 78 & 65 & 65 & 29 & 8 & 4 & -\end{array}$

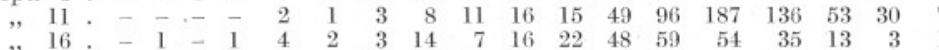

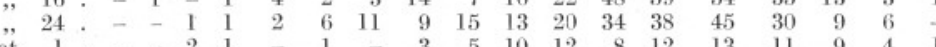

Oet. 1 - -2

$", 14:-5-14$

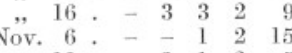

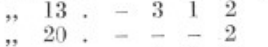

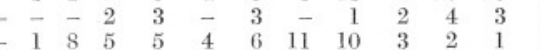

$\begin{array}{rrrrrrrr}4 & 6 & 11 & 10 & 3 & 2 & 1 & 1\end{array}$

,$\quad 17$

$\begin{array}{lllllllll}20 & 30 & 37 & 30 & 33 & 32 & 25 & 20 & 16\end{array}$

$\begin{array}{rrrrrrrrrrrr}- & 3 & 5 & 10 & 12 & 8 & 12 & 13 & 11 & 9 & 4 & \\ 1 & 1 & 6 & 1 & 6 & 7 & 9 & 16 & 15 & 8 & 2\end{array}$

$\begin{array}{llllllllllll}1 & 11 & 18 & 16 & 27 & 19 & 22 & 22 & 24 & 14 & 21 & 7\end{array}$

$\begin{array}{llllllllllllll}6 & 14 & 15 & 23 & 24 & 31 & 23 & 14 & 6 & 3 & 4 & 4 & 1 & \\ & 10 & 11 & 49 & 49 & 73 & 85 & 59 & 30 & 28 & 10 & 7 & -\end{array}$

$\begin{array}{rrr}28 & 10 & 7 \\ 18 & 5 & 6\end{array}$ 


\section{TABLE III-continued.}

Length in $\mathrm{mm}$.

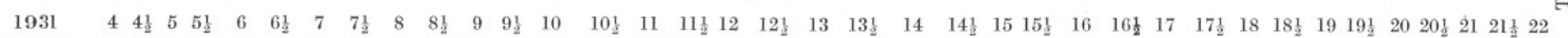

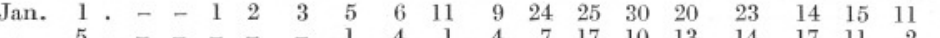

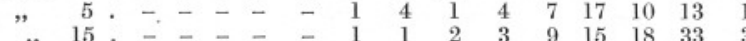

Feb. $\begin{array}{r}26 \\ 6\end{array}$

岁 $\quad$, 12 .

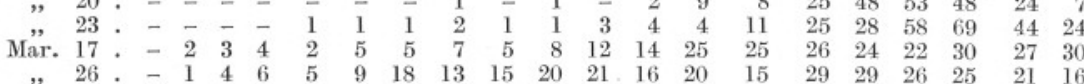
$\begin{array}{rrrrrrrrrrrrrrrrr}- & -3 & 3 & 3 & 3 & 7 & 11 & 8 & 19 & 17 & 17 & 12 & 15 & 15 & 9 & 10 & 16\end{array}$

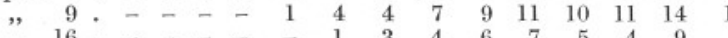

" 16.

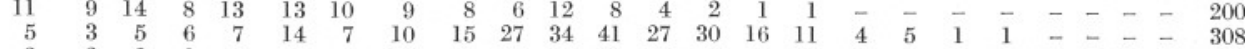

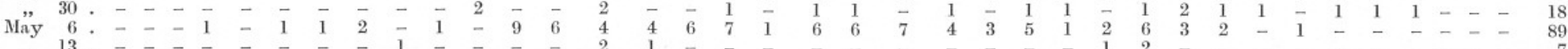

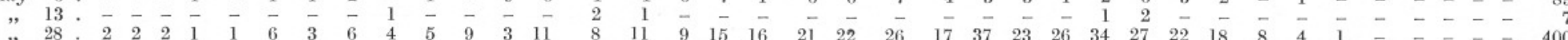


